Short Communication

\title{
Simplified Gas Diffusion Electrode Method for Proton Exchange Membrane Water Electrolysis with a ultralow Pt loading
}

\author{
Xiaofeng Xie, Shusheng Chen, Yuanquan Zhou, Xiaohong Hu* \\ Hubei Key Lab of Electrochemical Power Source, College of Chemistry and Molecular Sciences, \\ Wuhan University. Wuhan Hubei, 430072, China \\ *E-mail: xhhu88@whu.edu.cn
}

doi: $10.20964 / 2020.03 .14$

Received: 14 October 2019 / Accepted: 11 December 2019 / Published: 10 February 2020

Proton electrolyte membrane water electrolysis is a promising choice of hydrogen energy while limited by the high cost. Low Pt loading and large-scale application are practical for economic consideration. Here we replace the typical hydrophobic agent polytetrafluoroethylene (PTFE) with commercial fluorinated carbon $(\mathrm{CFx})$ to fabricate hydrogen evolution reaction electrodes with a simplified gas diffusion electrode method. The Pt loading can be reduced as low as $0.03 \mathrm{mg} \mathrm{cm}^{-2}$ without performance loss, and the electrode fabrication method is easy for mass production. Cyclic voltammetry shows CFx electrode has a high Pt Electrochemical surface area (ECSA) as much as $321 \mathrm{~m}^{2} \mathrm{~g}^{-1}$, and larger than that of PTFE electrode, the Pt utilization increases $12 \%$. Besides, scanning electron microscopy and pore analysis indicate the excellent performance of CFx electrode is related to the more reasonable threephase boundaries, especially for the improved proton transfer. In addition, the performance differs with the ratio of CFx and content of CFx. We believe the application of CFx in proton exchange membrane water electrolysis has great economic potential due to the ultralow Pt consumption and easy electrode fabrication process.

Keywords: Proton electrolyte membrane water electrolysis; Gas diffusion electrode; Three-phase boundaries; Ultralow Pt loading; Fluorinated acetylene black.

\section{$\underline{\text { FULL TEXT }}$}

(C) 2020 The Authors. Published by ESG (www.electrochemsci.org). This article is an open access article distributed under the terms and conditions of the Creative Commons Attribution license (http://creativecommons.org/licenses/by/4.0/). 